\title{
GLOBALIZAÇÃO, UNCTAD, OMC E OS ACORDOS DAS NAÇÕES UNIDAS PARA O DESENVOLVIMENTO
}

\author{
GLOBALIZATION, UNCTAD, WTO AND THE UNITED NATIONS DEVELOPMENT \\ AGREEMENTS
}

\author{
Ricardo Hasson Sayeg ${ }^{1}$ \\ Josimary Rocha de Vilhena ${ }^{2}$
}

\begin{abstract}
RESUMO: O presente artigo tem por objeto o estudo sobre a importância das Instituições Internacionais e seus tratados como antídoto contra a tensão desagregadora do Mundo Globalizado, abordando especificamente a relevância da UNCTAD e da OMC, interpretadas a partir do acordo da Nações Unidas para o Desenvolvimento, como instrumentos de neutralização das diferenças mundiais - visualizadas pela vitrine "global" -, bem como, direcionar as Nações da "aldeia" mundial para o caminho do Desenvolvimento e da paz, partindo do pressuposto de que o desenvolvimento figura como verdadeiro remédio para diminuir a miséria e a desigualdade no mundo. Trata-se de estudo descritivo e exploratório, realizado com base em pesquisa doutrinária e legal, servindo-se do método indutivo.
\end{abstract}

PALAVRAS-CHAVE: Direito ao Desenvolvimento. Direito Humano Inalienável. Globalização. UNCTAD. OMC.

ABSTRACT: This paper aims to analyze the importance of international instutions and other treaties, in particular the UNCTAD and the WTO, both interpreted by the scope of the UN charter, as instruments to neutralize the effects of globaly vizualized inequalities, as well as an antidote to combat the desagregating tensions of the Globalized World, therefore directing the nations as a world "tribe" towards the path of development and peace, as it is presumed that development is the path for decreasing global inequalities. This paper is a descriptive and explanatory piece, which, utilizing the inductive method, sourced both legal and doctrinal sources.

\footnotetext{
${ }^{1}$ Professor Livre Docente de Direitos Humanos - Mestrado e Doutorado - da Pontifícia Universidade Católica de São Paulo. Coordenador no Bacharelado da Disciplina de Direito Econômico do Departamento de Ciências Tributárias, Econômicas e Comerciais da Faculdade de Direito da PUC-SP e também membro dos Núcleos de Pesquisa no Programa de Doutorado e Mestrado de Direitos Humanos e Filosofia do Direito. Líder do Grupo de Pesquisa Capitalismo Humanista certificado pelo CNPq atuante na PUC-SP. Presidente do Instituto do Capitalismo Humanista. Titular da Cadeira 32 da Academia Paulista de Direito, da qual é Presidente do Conselho Fiscal.

${ }^{2}$ Advogada, Doutoranda em Direito pela PUC/SP, Mestre em Direito - Universidade Católica de São Paulo PUC. Pós-Graduação em Direito Público - Universidade Candido Mendes, UCAM-DF. Graduada em Direito. Autora do livro Direito Humano à Oportunidade . Rio de Janeiro: Lumen Juris, 2016). Pesquisadora membro do Grupo de Pesquisa Capitalismo Humanista PUC-SP.
} 


\title{
SUMÁRIO: INTRODUÇÃO - 1. O PAPEL DA CONFERÊNCIA DAS NAÇÕES UNIDAS SOBRE COMÉRCIO E DESENVOLVIMENTO - UNCTAD - 2. DA CRIAÇÃO DA OMC E SUA IMPORTÂNCIA PARA O CUMPRIMENTO DAS REGRAS INTERNACIONAIS - 3. DIFERENÇAS ENTRE O DIREITO AO DESENVOLVIMENTO E O DIREITO DO DESENVOLVIMENTO - 4. DOS ACORDOS DAS NAÇÕES UNIDAS PARA O DESENVOLVIMENTO - 5. CONCLUSÃO - REFERÊNCIAS BIBLIOGRÁFICAS - WEBGRAFIA
}

\section{INTRODUÇÃO}

Octávio Ianni, considerado dos maiores estudiosos do fenômeno da Globalização no Brasil, apresenta o conceito de Globalização, como sendo "uma última etapa do capitalismo", cuja característica é a expansão das telecomunicações e ocidentalização mundial, que, ainda sob a perspectiva do autor, alcançaria até mesmo o Oriente.

Metaforicamente, Ianni nomina de "fábrica" o sistema global, afirmando que:

\begin{abstract}
A fábrica global instala-se além de toda e qualquer fronteira, articulando capital, tecnologia, força de trabalho, divisão do trabalho social e outras forças produtivas. Acompanhada pela publicidade, a mídia impressa e eletrônica, a indústria cultural, misturadas em jornais, revistas, livros, programas de rádio, emissões de televisão, videoclipes, fax, redes de computadores e outros meios de comunicação, informação e fabulação, dissolve fronteiras, agiliza os mercados, generaliza o consumismo. Provoca a desterritorialização e reterritorialização das coisas, gentes e ideias. Promove o redimensionamento de espaços e tempos. ${ }^{3}$
\end{abstract}

Ao falar das consequências do fenômeno, Ianni argumenta que a globalização em curso, ao mesmo tempo em que integra e articula - diminuindo distâncias e agregando o mundo - em uma "aldeia global", considera, porém, que a Globalização possui o imenso potencial de "desagregar e tensionar" o mundo, como um todo, reproduzindo e acentuando desigualdades e antagonismos, polarizando grupos, classes, etnias, minorias e outros setores da sociedade.

\footnotetext{
${ }^{3}$ IANNI, Octávio. Teorias da Globalização, Rio de Janeiro, Civilização brasileira, 1996.
} 
De fato, a Globalização culmina em espécie de transcendência mundial das fronteiras dos Estados, emergindo uma "transfronteirização", e, com a "quebra" das fronteiras, naturalmente os conflitos individuais das Nações passam a emergir, surgindo assim, a premente necessidade de regulamentação internacional que permeie as relações humanas, nos diversos campos sociais.

É que os interesses dos Estados se confrontam nessa "rede" criada pelas transformações não somente econômicas, mas também socioculturais.

Nesse cenário mundial, a Globalização criou fenômeno estruturante capaz de compor o eixo central das transformações mundiais, precipuamente pela hipotética facilidade de as relações econômicas atravessarem as fronteiras.

E, em tal cenário, surge nova ordem nas relações sociais mundiais, vez que, a economia mundial - agora globalizada - necessita ser pautada no eixo das relações humanas, voltada aos direitos humanos, e à manutenção da paz:

Podemos dizer que enquanto a globalização conduz à paz, ao diminuir os incentivos para o conflito, o protecionismo baseia-se numa mentalidade e em políticas que enfatizam os interesses divergentes das nações. Ou como diria Tom Palmer, o comércio livre une os países em paz. Daí o velho adágio que diz 'quando os bens não podem atravessas as fronteiras, os exércitos certamente o farão'.

O comércio conduz a benefícios para todos, mas isso só acontece se as pessoas virem os outros seres humanos como parceiros numa cooperação mutuamente benéfica, e, não como rivais mortais. Só assim a sociedade humana se torna possível e o comércio pode ser visto como base primordial da civilização humana".

Os defensores de governos democráticos deveriam estar abetos ao comércio e à globalização até como forma de reforçar o Estado de Direito e incentivar a persuasão (versus força) e todas as formas voluntárias de serviço aos outros. Infelizmente, os antiglobalizadores e os protecionistas, em em vez de considerarem o comércio livre um direito humano, partem do pressuposto que têm o direito de suar a força para evitar que cada um de nós se beneficie com a contínua realização de trocas voluntárias. ${ }^{4}$

Daí a importância da intervenção das Organizações Mundiais e dos Tratados Internacionais para a coordenação desse movimento, dentro de parâmetro ético-legal voltado

\footnotetext{
${ }^{4}$ MOREIRA. José Manoel. Equívocos sobre o capitalismo e a globalização. Revista de Economia e Relações Internacionais. Faculdade de Economia da Fundação Armando Alvares Penteado. São Paulo. V. 6, p. 90-106, jul. 2007
} 
para o desenvolvimento das relações humanas, como pressuposto do mundo globalizado que se paute no Direito ao Desenvolvimento.

Pois, se de um lado o avanço do comércio globalizado naturalmente traz o embate entre os acordos comerciais - pelo caráter econômico puro das relações de comércio -, e os tratados de direitos humanos, também é verdade que os Organismos Internacionais precisam ser firmes em dirimir os conflitos sem barrar o desenvolvimento, em justaposição de interesses para o benefício da humanidade, quando o foco é dividido entre o crescimento econômico e o ser humano.

\section{O PAPEL DA CONFERÊNCIA DAS NAÇÕES UNIDAS SOBRE COMÉRCIO E DESENVOLVIMENTO - UNCTAD}

A Conferência das Nações Unidas sobre Comércio e Desenvolvimento (UNCTAD) estabelecida em 1964, em Genebra, Suíça, atendendo às reclamações dos países em desenvolvimento, foi instituída com a finalidade precípua de estabelecer foro internacional permanente para tratar as questões de desenvolvimento e comércio internacional. ${ }^{5}$

Um dos discursos vigentes na época que impulsionaram a concretização da Conferência foi o prejuízo alegado pelos Países que não faziam parte nas negociações do Acordo Geral sobre Tarifas e Comércio (GATT, sigla em inglês).

Desde então, a UNCTAD passou a ser o principal órgão das Nações Unidas para tratamento integrado entre comércio e desenvolvimento, assim, como dos temas correlacionados às áreas de finanças, tecnologia, investimento e desenvolvimento sustentável.

Essa primeira reunião da $\mathrm{UNCTAD}^{6}$ (United Nations Conference on Trade and Development) foi crucial para a consolidação do conceito do "Direito ao Desenvolvimento".

Nesse sentido, Cecília Kaneto Oliveira, pondera que:

\footnotetext{
${ }^{5}$ CONFERÊNCIA DAS NAÇÕES UNIDAS SOBRE O COMÉRCIO E DESENVOLVIMENTO - UNCTAD. Disponível em:

http://www.agricultura.gov.br/pls/portal/docs/PAGE/MAPA/MENU LATERAL/AGRICULTURA PECUARI A/RELACOES_INTERNACIONAIS/NEGOCIACOES_COMERCIAIS/ORG_INTER/UNCTAD/A\%20UNCT AD\%200\%20SGP\%20E\%200\%2 SGPC_0.PDF. Acesso em 27 de agosto de 2018.

6 A sigla em língua portuguesa é CNUCED (Conferência das Nações Unidas para o Comércio e o Desenvolvimento). No entanto, no Brasil a sigla mais utilizada é a em língua inglesa, e por este motivo, ao longo do trabalho, cita-se a Conferência através da sigla UNCTAD.
} 
[...] o discurso dos países em desenvolvimento à época da criação da UNCTAD conduziu ao caminho para o reconhecimento do direito ao desenvolvimento. [...] A busca efetiva por uma igualdade efetiva entre os países e não apenas formal, ou seja, a tentativa de implementação de um tratamento diferente para os Estados distintos fundamentou a ideia de um direito ao desenvolvimento. ${ }^{7}$

Do sitio oficial do Itamaraty, se retira o importante conceito da UNCTAD e sua missão, constando que se trata de órgão das Nações Unidas com mandato específico para tratar da relação entre comércio internacional e desenvolvimento.

Segundo narra o Itamaraty, a legitimidade da UNCTAD se confirma e se consolida pela participação de países desenvolvidos e em desenvolvimento em seus trabalhos.

A expectativa do Brasil é a de que sejam mantidas, reforçadas e desenvolvidas, as atividades referentes aos três pilares da Conferência: formação de consenso, cooperação técnica e pesquisa e análise sobre desenvolvimento.

A cada quatro anos, os países membros, que são todos os países das Nações Unidas, se reúnem em conferência para definir as orientações estratégicas do próximo período de trabalhos. Atualmente, vigora o mandato da XIV UNCTAD, realizada em Nairóbi, em 2016.

Os programas definidos pela Conferência são executados pelo Secretariado, órgão responsável pelos serviços técnico e substantivo de apoio ao cumprimento do mandato da Conferência. As unidades do Secretariado assistem à Junta de Comércio e Desenvolvimento, órgão intergovernamental permanente, ao qual se subordinam duas comissões temáticas, a saber: Comissão de Comércio e Desenvolvimento; e Comissão de Investimento, Empreendedorismo e Desenvolvimento. As Comissões podem convocar reuniões de peritos, com a finalidade de aprofundar as discussões técnicas.

A UNCTAD possui importante papel na realização de pesquisas e discussão intergovernamental em temas como produtos de base, comércio internacional de bens e serviços, investimentos, política da concorrência, entre outros, buscando analisar e trazer à discussão os temas relevantes da agenda econômica internacional, desde a perspectiva dos países em desenvolvimento. ${ }^{8}$

\footnotetext{
${ }^{7}$ OLIVEIRA, Cecília Kaneto. A UNCTAD e sua contribuição para o direito ao desenvolvimento. In: BARRA, Welber; PIMENTEL, Luiz Otávio; CORREA, Carlos M. Direito, Desenvolvimento e Sistema Multilateral de Comércio. Florianópolis: Fundação Boiteux, 2008. p. 151.

8 Disponível em :http://www.itamaraty.gov.br/pt-BR/politica-externa/diplomacia-economica-comercial-efinanceira/15585-a-unctad-e-o-sgpc, acesso aos 10.11.18.
} 
Ricardo Sayeg e Wagner Balera, esclarecem o papel idealizado para a UNCTAD, bem como, as problemáticas para a concretização de sua finalidade:

Na linha da pacificação pela via econômica, é instituída em 1964 a Conferência das Nações Unidas para o Comércio e o Desenvolvimento (UNCTAD), incumbida de promover a integração dos países em desenvolvimento à economia mundial. Nesse importante mandato recebido pela UNCTAD já é possível identificar a inflexão da ONU em direção à integração econômica entre os povos e ao desenvolvimento global. Pode-se dizer que foi esse o primeiro passo dado pela ONU para transformar-se, a seu tempo, no ente capacitado a orientar o mundo no caminho da globalização que, àquela altura, ainda não fora colocada em perspectiva futura

É forçoso reconhecer, porém, que tal como o GATT, também a UNCTAD não recebeu poderes para atuar em favor da efetiva humanização do comércio. ${ }^{9}$

É inegável, no entanto, que a UNCTAD tem grande importância por ter servido de fórum para a elaboração do conceito de desenvolvimento, além de vinculá-lo ao comércio internacional, que, segundo ainda segundo Oliveira, "passaria a ser melhor regulamentado três décadas depois com o surgimento da OMC".

\section{DA CRIAÇÃO DA OMC E SUA IMPORTÂNCIA PARA O CUMPRIMENTO DAS REGRAS INTERNACIONAIS}

Do sítio eletrônico oficial da World Trade Organization (WTO) ${ }^{10}$ se retira que a OMC é a única Organização Global Internacional que trabalha com as regras internacionais do comércio entre as Nações.

No preâmbulo do seu acordo constitutivo, os Estados-Membros reconheceram que as suas relações no domínio comercial e econômico deveriam ser conduzidas a fim de elevar os padrões de vida, assegurando o pleno emprego e resultados equitativos para os países em desenvolvimento, de acordo com os objetivos do desenvolvimento sustentável.

Quanto a importância da criação da OMC, Marcelo Varella destaca que:

\footnotetext{
${ }^{9}$ SAYEG, Ricardo. BALERA, Wagner. O Capitalismo Humanista. São Paulo: Petrópolis, 2011, p. 61

102 Disponível em: https://www.wto.org/english/thewto_e/whatis_e/who_we_are_e.htm, acesso em: 01 de nov. 2018.
} 
A criação da Organização Mundial do Comércio talvez seja o principal resultado do multilateralismo econômico no campo jurídico. A fundação da OMC revive a ideia de construção de um cenário de paz, a partir da maior integração econômica global e do próprio crescimento mundial com o fortalecimento do comércio e do liberalismo econômico, dentro de um espírito kantiano."

$[\ldots]$

Os tribunais mais antigos também desenvolveram mecanismos de reforço dos instrumentos de indução ao cumprimento. De um lado, ganharam força nos últimos 20 anos porque vários países ratificaram tratados, aceitando a sua jurisdição, como a ampliação da competência da Corte de Justiça das Comunidades Europeias, do Tribunal da União Europeia e da Corte Interamericana de Direitos Humanos. De outro, reforçaram o caráter obrigatório de suas decisões, como a Corte Internacional de Justiça, a partir do contencioso Estados Unidos-LaGrand, quando afirmou pela primeira vez a obrigatoriedade de suas decisões, o que nunca havia feito nos cinquenta anos anteriores. Os mecanismos de indução ao cumprimento destes tribunais mais antigos, contudo, ainda são bem menos efetivos do que aqueles dos novos tribunais. ${ }^{11}$,

Varela esclarece ainda, que a OMC é importante instrumento de cumprimento das decisões internacionais, destacando-se seu direito como processo de transformação do direito internacional das relações comerciais, especialmente após 1990, e tudo dentro de mudança de orientação lógica das práticas comerciais e dentro de ampliação da importância que é ter um sistema orientado por regras jurídicas internacionais claras.

Por sua vez, Sayeg e Balera contextualizam a criação da OMC como tendo sido "um dos mais relevantes acontecimentos daquela década."

Consagra-se, na sequência, a globalização econômica neoliberal, quando em 1995 é instalada, como decorrência da Rodada Uruguai, a Organização Mundial do Comércio (OMC) — que, com traços de solidarismo, adotou timidamente o princípio do tratamento especial e diferenciado para países em desenvolvimento estabelecido no Artigo XXVIII e na Parte IV do GATT/1994." 12

Continuando, defendem que "por este princípio, os países em desenvolvimento teriam vantagens tarifárias, além de medidas mais favoráveis a serem aplicadas pelos países desenvolvidos.

${ }^{11}$ VARELLA, Marcelo D.. Dificuldades de implementação das decisões da OMC: um estudo de caso a partir do contencioso pneus. Rev. direito $G V$ [online]. 2014, vol.10, n.1.

${ }^{12}$ SAYEG e BALERA, op citada, p. 63-65 
Mas o mecanismo mais importante de tantos quantos tenham sido criados na estrutura moderna da OMC talvez seja o denominado Sistema de Resolução de Controvérsias. Por força de tal mecanismo, a segurança e a previsibilidade do sistema multilateral de comércio, pacientemente engendrado pela normativa da OMC, passaram a encontrar instância pertinente de deliberação para a resolução de controvérsias, por meio da busca de consenso entre os árbitros do Painel instituído no âmbito do Órgão de Solução de Controvérsias e, eventualmente, pelo Corpo de Apelação, que foi firmando jurisprudência marcadamente neoliberal. ${ }^{13}$

Finalizam dizendo que:

No novo marco negocial da sociedade global, seriam objeto de entendimento os mais diferentes assuntos, com a consagração da globalização econômica neoliberal. Tratou-se de: agricultura; aplicação de medidas sanitárias e fitossanitárias; têxteis e confecções; barreiras técnicas ao comércio; medidas de investimento relacionadas ao comércio; antidumping; valoração aduaneira; inspeção de pré-embarque; regras de origem; procedimentos relativos a licenças de importação; salvaguardas; subsídios e medidas compensatórias. Nessa peia neoliberal, devido à importância assumida pelo setor de serviços, o GATT/1994 compreendeu, ainda, o acordo-quadro sobre o Comércio de Serviços (GATS), além do Acordo sobre Aspectos dos Direitos de Propriedade Intelectual Relacionados ao Comércio (TRIPS). ${ }^{14}$

Não se pode olvidar a missão da OMC na concretização das relações humanas de comércio, com o cumprimento aos tratados internacionais do direito ao Desenvolvimento, pertencente à terceira dimensão dos direitos humanos.

Do sitio da ONU no Brasil, se extrai a meta de que relações comerciais devem ser integradas aos acordos de direitos humanos, e, nas palavras de Alfred Zayas, o Conselho de Direitos Humanos deve ter ciência dos tratados e das normas internacionais, de arte a impedir que sejam violadas, sob pena de enfraquecimento do Estado Democrático de Direito:

O relator especial das Nações Unidas sobre a promoção de uma ordem internacional democrática e equitativa, Alfred de Zayas, pediu que os governos e parlamentos garantam que todos os futuros acordos comerciais estipulem a primazia dos direitos humanos.

\footnotetext{
${ }^{13}$ SAYEG e BALERA, op citada, p. 63-65

${ }^{14}$ SAYEG e BALERA, op citada, p. 63-65
} 
Segundo o relator, os acordos existentes devem ser revistos para garantir que eles não entrem em conflito com o dever dos Estados-membros da ONU de cumprir os tratados de direitos humanos e de cumprir as metas ambientais e de saúde.

"Em caso de conflito, é preciso dar prioridade à aceleração do interesse público em vez de continuar com a ênfase atual sobre as expectativas de lucro dos investidores e das empresas transnacionais", acrescentou.

De acordo com o relator especial, é imprescindível que os direitos humanos sejam integrados o quanto antes aos acordos comerciais e às regras e regulamentos da Organização Mundial do Comércio (OMC), de modo que os representantes do comércio saibam que o comércio não é um regime solitário.

“O 'fórum público' anual da OMC é demorado, mas seguramente contribui para o reforço da consciência das preocupações da sociedade civil. Sociedade civil, incluindo sindicatos de consumidores, profissionais de saúde, grupos ambientais e outras partes interessadas, devem fazer parte do processo de elaboração, negociação, adoção e implementação de acordos comerciais", frisou.

O especialista lembrou que muitos direitos humanos básicos são negativamente impactados pelos acordos comerciais e pelas decisões arbitrárias, tais como o direito à autodeterminação e soberania sobre riquezas e recursos naturais (especialmente das populações indígenas); o direito à vida e à saúde, por exemplo, quando o acesso a medicamentos genéricos é impedido; o direito ao trabalho; o direito a condições de trabalho humanas; o direito de acesso à informação - incluindo sobre os tratados comerciais; o direito de reunião pacífica e de associação e o direito à participação do público. ${ }^{15}$

Ainda segundo aquele expert: "a ordem mundial justa, pacífica e democrática" não pode ceder espaço pelas atividades de investidores, especuladores e empresas transnacionais "ávidos por lucro imediato", sendo este dos principais desafios da economia globalizada, rumo a consolidação do direito ao desenvolvimento, enquanto parte integrante dos direitos humanos inalienáveis.

Sem embargo dos relevantes avanços na esfera comercial internacional, a OMC se encontra em momento decisivo da sua história.

À medida em que a globalização inova os limites, que já não mais são "territoriais", também os desafios da OMC ganham proporções globais, diante de seu papel em assegurar relações comerciais lucrativas e humanizadas.

\footnotetext{
${ }^{15}$ Disponível em: https://nacoesunidas.org/direitos-humanos-devem-ser-integrados-a-acordos-comerciais-alertarelator-da-onul, visitado em: 10.11.2018
} 
E se é verdade que as relações comerciais inovam nas regras de expansão e acesso, também, novas dimensões dos Direitos Humanos vão, gradativamente, sendo internacionalmente pactuadas.

Neste cenário, a OMC é chamada a se posicionar sobre questões que transcendem o âmbito meramente mercantil de suas ações, mas que estão intrinsicamente ligadas ao comércio internacional responsável, voltado ao desenvolvimento social e sustentável das nações.

Assim, questões como direitos e garantias trabalhistas, proteção do meio ambiente, dignidade da pessoa humana, desenvolvimento, erradicação da pobreza são trazidas à baila, engradecendo os debates no âmbito mundial, inclusive quanto ao alcance e conceito de desenvolvimento.

\section{DIFERENÇAS ENTRE O DIREITO AO DESENVOLVIMENTO E O DIREITO DO DESENVOLVIMENTO}

Robério Nunes dos Anjos Filho ${ }^{16}$ defende haver diferença entre os dois conceitos, afirmando que "O Direito Internacional do Desenvolvimento é um ramo do Direito Internacional Público". Tal ramo surgiu na década de 60, durante as Conferências das Nações Unidas sobre Comércio e Desenvolvimento (UNCTAD) e recaindo, tal como já explorado, sobre relações interestatais e tem como titulares os países em desenvolvimento.

O pensador afirma que este objetiva a construção de uma Nova Ordem Econômica Internacional, favorável aos países subdesenvolvidos, com base na cooperação internacional e em privilégios comerciais não extensíveis aos demais países (Sistema Geral de Preferências), contornando a cláusula da nação mais favorecida do GATT. Os países desenvolvidos passaram a poder conceder, unilateralmente e sem exigência de reciprocidade, isenções ou reduções de tarifas de importação incidentes sobre produtos exportados pelos países subdesenvolvidos.

16 FILHO, Robério Nunes dos Anjos. "Direito ao Desenvolvimento" Ed. SARAIVA, 2013 
Nesse sentido, Fernando Antônio Amaral Cardia ${ }^{17}$, afirma que na década de 1960 nasce "[...] o Direito do Desenvolvimento, como um programa normativo de cooperação em diversas áreas das relações econômicas, com vistas a superar as profundas diferenças de desenvolvimento existentes entre os povos do mundo".

Já o Direito ao desenvolvimento "é um direito humano de terceira dimensão e, portanto, possui foco direto no ser humano, na pessoa, sob o ponto de vista individual ou coletivo (povos, coletividades regionais internas, grupos vulneráveis, minorias)”, e está vinculado a uma melhoria qualitativa das condições de vida.

Ana Paula Teixeira Delgado ${ }^{18}$ em sua tese de mestrado, ao tratar do desenvolvimento sob o ângulo da Globalização afirma que é grave o fato de o direito ao desenvolvimento ser associado apenas ao crescimento econômico, em detrimento de suas dimensões sociais, culturais e políticas, de suma importância no que concerne ao processo de capacitação das pessoas, compreendendo-se aí aspectos como a educação, o conhecimento, a justiça social, a participação pública e o fortalecimento das instituições democráticas.

Em síntese, compreender o desenvolvimento como direito humano implica a reconstrução do próprio conceito de desenvolvimento, que não se resume apenas ao crescimento econômico.

Com efeito, aponta Balera:

O consenso em torno do desenvolvimento decorre da respectiva afirmação como parte integrante e necessária do catálogo universal dos direitos humanos. ${ }^{19}$

Ao mesmo tempo em que, se encontra intimamente ligado ao conceito de economia humanizada e acessível aos membros da sociedade globalizada.

\section{DOS ACORDOS DAS NAÇÕES UNIDAS PARA O DESENVOLVIMENTO}

\footnotetext{
17 CARDIA, Fernando Antonio Amaral. Uma breve introdução à questão do desenvolvimento como tema de Direito Internacional. In.: AMARAL JÚNIOR, Alberto (Org). Direito Internacional e Desenvolvimento. Barueri: Manole, 2005. p. 57.

18 DELGADO, Ana Paula Teixeira. O direito ao desenvolvimento na perspectiva da globalização: paradoxos e desafios. Rio de Janeiro: Renovar, 2001, p. 105-106.

${ }^{19}$ BALERA, Wagner. Declaração sobre o Direito ao Desenvolvimento Anotada. Curitiba: Juruá. 2, 2018 , p. 19.
} 
Antes mesmo que houvesse condições ideais para a que as discussões sobre o direito ao desenvolvimento, como dimensão dos direitos humanos fossem popularizadas, inúmeros foram os textos internacionais que positivaram os diversos princípios morais, voltados para a lógica do desenvolvimento sob o manto dos "Direitos Humanos".

Merece destaque, a Encíclica papal "Populorum progressio", publicada pelo Papa Paulo VI ${ }^{20}$ em 1967, cujo escopo é o desenvolvimento dos povos, que deve ser dar numa "ação organizada para o desenvolvimento integral do homem e para o desenvolvimento integral da humanidade".

[...] o desenvolvimento não se reduz a um simples crescimento econômico. Para ser autêntico, deve ser integral, quer dizer, promover todos os homens e o homem todo, como justa e vincadamente sublinhou um eminente especialista: 'não aceitamos que o econômico se separe do humano; nem o desenvolvimento, das civilizações em que ele se incluiu. O que conta para nós é o homem, cada homem, cada grupo de homens, até se chegar à humanidade inteira"”

Trata-se de marco de discussão do direito ao desenvolvimento, uma vez que, o mais importante líder mundial cristão da época, demonstrou a preocupação e compromisso da igreja católica com a difusão e a busca do desenvolvimento dos povos.

Já no âmbito da Organização das Nações Unidas, o primeiro documento a fazer menção expressa ao tema foi a Resolução n 4 de 21 de fevereiro de 1977 da Comissão de Direitos Humanos, que pela primeira vez reconheceu de forma oficial a importância do Direito ao Desenvolvimento.

Em 1979, a Comissão de Direitos Humanos (resolução ${ }^{\circ}{ }^{5}$ ) reiterou o entendimento anterior e reafirmou que "o direito ao desenvolvimento é um direito humano e que a igualdade de oportunidades é uma prerrogativa tanto das nações como dos indivíduos que formem as nações". ${ }^{21}$

20 PAULO VI. Carta encíclica Populorum progressio. 26 de março de 1967. Publicação em homenagem aos seus quarenta anos. Centro de Documentação Eletrônica Beato João XXIII. São Paulo, 2007.

21 PEIXINHO, Manoel Messias; FERRARO, Suzani Andrade. Direito ao Desenvolvimento como Direito Fundamental. Anais do XVI Congresso Nacional do CONPEDI, Belo Horizonte, p. 6952-6973, 2007. 
Em 1982, a Assembleia Geral da ONU ${ }^{22}$ (Resolução 37/199) perfilhou importantes padrões referentes ao Direito ao Desenvolvimento como Direito Humano inalienável, colocando a paz e a segurança internacional como elementos essenciais para a garantia deste Direito.

Em um outro trecho, a mesma Resolução declarou o entendimento de que o "fim último do desenvolvimento é o aumento constante do bem-estar de toda a população sobre a base de sua plena participação no processo de desenvolvimento e de uma justa distribuição dos benefícios do mesmo".

Quatro anos depois, em 1986, a ONU aprovou a Declaração sobre o Direito ao Desenvolvimento. No início de seu texto o art. $1^{\circ}$ confere ao desenvolvimento status de direito humano inalienável, conforme transcrição abaixo:

\begin{abstract}
Artigo $1^{\circ}(\ldots)$
$\S 1$ - O direito ao desenvolvimento é um direito humano inalienável, em virtude do qual toda pessoa e todos os povos estão habilitados a participar do desenvolvimento econômico, social, cultural e político, a ele contribuir e dele desfrutar, no qual todos os direitos humanos e liberdades fundamentais possam ser plenamente realizados.
\end{abstract}

Sobre a importância das relações econômicas e sua relação com o direito ao desenvolvimento, Patrícia de Oliveira Areas $^{23}$, aponta o crescimento econômico ao lado do desenvolvimento social para que se alcance o desenvolvimento pleno.

[...] para que haja desenvolvimento, é mister que se promova, juntamente com o crescimento econômico, o desenvolvimento humano, social, sustentável e o fortalecimento das instituições. $\mathrm{O}$ Direito e, consequentemente, as leis têm um papel primordial neste contexto, tendo em vista que estes fazem parte das instituições.

\footnotetext{
${ }^{22}$ Disponível em: http://www.faders.rs.gov.br/legislacao/6, acessado em 10.11.18.

${ }^{23}$ AREAS, Patrícia de Oliveira. Propriedade Intelectual do Software: Direito Moral e Desenvolvimento. In.: PIMENTEL, Luiz Otávio; BARRAL, Welber (Orgs). Propriedade Intelectual e
}

Desenvolvimento.Florianópolis: Fundação Boiteux, 2007. p. 113. 
Para Amartya $\mathrm{Sen}^{24}$, não basta o incremento dos níveis econômicos e sociais. É necessário que se tenha o controle das interferências externas realizadas por parte de Estados que adotam políticas imperialistas ou instituições internacionais, como o FMI ou Banco Mundial. O Direito deve atuar como regulador dessa liberdade a partir do momento em que o Desenvolvimento é encarado como Direito Humano inalienável, conferindo ainda eficácia ao Princípio da Soberania, que é uma das bases do Direito Internacional Público.

Contrário à teoria das gerações dos direitos, Cançado Trindade ${ }^{25}$ pondera que o Direito ao Desenvolvimento, quando recebe status de Direito Humano, passa a complementar toda gama de direitos preexistentes, e não a suceder os anteriores.

O autor afirma que:

"O direito ao desenvolvimento teve o propósito de fortalecer, jamais restringir, os direitos pré-existentes. Assim ocorre em razão da natureza complementar de todos os direitos humanos. [...] Assim, uma denegação do direito ao desenvolvimento há de acarretar consequências adversas para o exercício dos direitos civis e políticos assim como dos direitos econômicos, sociais e culturais. [...] O fenômeno que hoje testemunhamos não é o de uma sucessão geracional imaginária (a infundada teoria das gerações de direitos), mas antes o da expansão e fortalecimento dos direitos humanos reconhecidos."

Em 2015, As Nações Unidas definiram os Objetivos de Desenvolvimento Sustentável (ODS) como parte da nova agenda de desenvolvimento sustentável que deve finalizar o trabalho dos ODM é "não deixar ninguém para trás".

Sayeg ${ }^{26}$ e Balera, afirmam que: "Desenvolvidos são os países em que todo o povo está inserido na evolução política, econômica, social e cultural, conquistando acesso a níveis

\footnotetext{
${ }^{24}$ SEN, Amartya. Desenvolvimento como liberdade. São Paulo: Companhia das Letras, 2000., tradução de Laura T. Mota. P. 18.

${ }^{25}$ TRINDADE, Antônio Augusto Cançado. Tratado de Direito Internacional dos Direitos Humanos.

Vol. II. Porto Alegre: Sério Antonio Fabris Editor, 1999. p. 281.

${ }^{26}$ SAYEG e BALERA, op citada, p. 177.
} 
de vida que atendam, pelo menos, ao mínimo vital, e em que haja respeito à humanidade e ao planeta."

\section{CONCLUSÃO}

Talvez, um dos maiores desafios apresentados com o processo - já avançado - da Sociedade Global, seja enfrentar as múltiplas variáveis da sociedade pós-nacional em um mosaico que consiga acomodar, simultaneamente, o velho e o novo, as vantagens capitalistas e as tradições de cada local, interpretadas a partir dessa realidade mundial de comércio unificado, sem descuidar dos direitos humanos.

Boaventura de Sousa Santos, sintetiza o desenvolvimento calcado na utilização inteligente das relações comerciais, ponderando como desafio:

[...] apontar as condições que permitem conferir aos direitos humanos tanto o caráter global quanto a legitimidade local, para fundar uma política progressista de direitos humanos - direitos humanos concebidos como a energia e a linguagem de esferas públicas locais, nacionais e transnacionais atuando em rede para garantir novas e mais intensas formas de inclusão social... ${ }^{27}$

Detectar - dentre todas as culturas - valores comuns, ou melhor, achar entre as diferenças os mínimos denominadores comuns, sempre tendo em vista a dignidade da pessoa humana, que passa, inclusive, pela promoção do desenvolvimento econômico - aspecto fundamental para a realização do ideário humanista - necessariamente perpassa pelo diálogo internacional das relações comerciais, e é tarefa árdua sopesar o crescimento do comércio mundial, sem descurar das necessidades básicas das hordas de miseráveis que povoam a maior parte do planeta, incluindo-os no plano de desenvolvimento humano.

A Declaração da ONU sobre Direitos Humanos, de 1993, já previa que "O progresso duradouro necessário à realização do direito ao desenvolvimento exige políticas eficazes de desenvolvimento em nível nacional, bem como relações econômicas equitativas e um ambiente econômico favorável em nível internacional”.

${ }^{27}$ SANTOS, Boaventura de Sousa. Reconhecer para libertar. Rio de Janeiro: Civilização Brasileira, 2003. p. 432. 
Em 1967, o sábio Papa Paulo VI, já sabia: A economia está a serviço do homem.

Josimary Vilhena ${ }^{28}$, no estudo do Direito a Oportunidade, sintetizou a necessária sintonia entre o mercado - agora globalizado - e o fundamento de sua correta aplicação à luz dos direitos humanos - afirmando que: "O direito vem humanizar a economia e dar balizas sociais à liberdade natural. Na linha do Direito Econômico, a denominação do "trabalho humano e da livre iniciativa" como fundamentos da ordem constitucional econômica vigente constitui a admissão desses dois valores como preceitos indissociáveis. E a análise conjunta desses dois fundamentos reflete na ordem jurídica como um todo, pressupondo-os como organismos motores da ordem social e dos direitos de todos."

Tal é a importância da correta interpretação desses dois organismos, cujo agir distorcido pode gerar cruéis e desumanas penas impostas à humanidade: a escravatura do ser humano - pelo próprio ser humano - que modernamente se dá através da miséria e da exclusão. Como diz Victor Hugo no poema "Desejo": é preciso que a humanidade verdadeiramente se conscientize de que ainda existem oprimidos, injustiçados e infelizes e de que eles estão à nossa volta. Mais que solidários, somos, na verdade, corresponsáveis pela perpetuação da miséria." 29

Diante desse quadro tão bem delimitado, é que se mostra arrazoado que a UNCTAD e a OMC - à luz dos preceitos fundamentais e dos tradados internacionais que promovem e asseguram o direito ao desenvolvimento, como dimensão indispensável dos direitos humanos - sejam utilizados como instrumento da estrutura globalizada na preciosa missão de universalização dos direitos humanos, resguardadas as liberdade e diferenças de cada povo, sem, no entanto, barrar o crescimento econômico, que, ao invés de distorcer e escravizar, precipuamente, deve diminuir os desníveis sociais, amenizando os conflitos naturais do crescimento por meio do diálogo das fontes do direito.

\section{REFERÊNCIAS BIBLIOGRÁFICAS}

AREAS, Patrícia de Oliveira. Propriedade Intelectual do Software: Direito Moral e Desenvolvimento. In.: PIMENTEL, Luiz Otávio; BARRAL, Welber (Orgs). Propriedade Intelectual e Desenvolvimento.Florianópolis: Fundação Boiteux, 2007.

\footnotetext{
${ }^{28}$ VILHENA. J. R. Direito Humano à Oportunidade. Rio De Janeiro: Lumen Juris, 2016, p. 79

${ }^{29}$ VILHENA, op. Citada, p.76
} 
CARDIA, Fernando Antonio Amaral. Uma breve introdução à questão do desenvolvimento como tema de Direito Internacional. In.: AMARAL JÚNIOR, Alberto (Org). Direito Internacional e Desenvolvimento. Barueri: Manole, 2005. p. 57.

DELGADO, Ana Paula Teixeira. O direito ao desenvolvimento na perspectiva da globalização: paradoxos e desafios. Rio de Janeiro: Renovar, 2001.

FILHO, Robério Nunes dos Anjos. Direito ao Desenvolvimento. Ed. SARAIVA, 2013.

IANNI, Octávio. Teorias da Globalização, Rio de Janeiro, Civilização brasileira, 1996.

MOREIRA. José Manoel. Equívocos sobre o capitalismo e a globalização. Revista de Economia e Relações Internacionais. Faculdade de Economia da Fundação Armando Alvares Penteado. São Paulo. jul. 2007

OLIVEIRA, Cecília Kaneto. A UNCTAD e sua contribuição para o direito ao desenvolvimento. In: BARRA, Welber; PIMENTEL, Luiz Otávio; CORREA, Carlos M. Direito, Desenvolvimento e Sistema Multilateral de Comércio. Florianópolis: Fundação Boiteux, 2008.

PAUlO VI, Carta encíclica Populorum progressio. 26 de março de 1967. Publicação em homenagem aos seus quarenta anos. Centro de Documentação Eletrônica Beato João XXIII. São Paulo, 2007.

PEIXINHO, Manoel Messias; FERRARO, Suzani Andrade. Direito ao Desenvolvimento como Direito Fundamental. Anais do XVI Congresso Nacional do CONPEDI, Belo Horizonte.

SANTOS, Boaventura de Sousa. Reconhecer para libertar. Rio de Janeiro: Civilização Brasileira, 2003.

SAYEG, Ricardo. BALERA, Wagner. O Capitalismo Humanista. São Paulo: Petrópolis, 2011.

SEN, Amartya. Desenvolvimento como liberdade. São Paulo: Companhia das Letras, 2000, tradução de Laura T. Mota.

TRINDADE, Antônio Augusto Cançado. Tratado de Direito Internacional dos Direitos Humanos. Vol. II. Porto Alegre: Sério Antonio Fabris Editor, 1999.

VARELLA, Marcelo D. Dificuldades de implementação das decisões da OMC: um estudo de caso a partir do contencioso pneus. Rev. direito GV [online]. 2014, vol.10, n.1.

VILHENA. Josimary Rocha de. Direito Humano à oportunidade. Rio De Janeiro: Lumen Juris, 2016.

\section{WEBGRAFIA}

CONFERÊNCIA DAS NAÇÕES UNIDAS SOBRE O COMÉRCIO E DESENVOLVIMENTO - UNCTAD. Disponível em:

http://www.agricultura.gov.br/pls/portal/docs/PAGE/MAPA/MENU_LATERAL/AGRICUL TURA_PECUARIA/RELACOES_INTERNACIONAIS/NEGOCIACOES_COMERCIAIS/O RG_INTER/UNCTAD/A\%20UNCTAD $\% 200 \% 20$ SGP $\% 20 E \% 200 \% 2 \quad$ SGPC_0.PDF. Acesso: 27.08.2018. 
CONJUNTO

DE

LEIS

Disponível

em:

https://www.wto.org/english/thewto_e/whatis_e/who_we_are_e.htm,

Acesso em: 01.11. 2018.

LEGISLAÇÃO Disponível em: http://www.faders.rs.gov.br/legislacao/6,

Acesso em 10.11.2018.

PÁGINA OFICIAL DO ITAMARATY Disponível em: http://www.itamaraty.gov.br/ptBR/politica-externa/diplomacia-economica-comercial-e-financeira/15585-a-unctad-e-o-sgpc,

Acesso aos 10.11.2018.

PÁGINA OFICIAL DA ONU NO BRASIL Disponível em: https://nacoesunidas.org/direitos-humanos-devem-ser-integrados-a-acordos-comerciais-alertarelator-da-onu/, Acesso em: 10.11.2018. 